\title{
UN PSICOANALISIS SE INICIA CUANDO EL PACIENTE SIENTE INTERRUMPIDO EL RELATO DE SU VIDA ${ }^{1}$
}

\author{
Rosa Velasco ${ }^{2}$ \\ SEP/IPA, IARPP-E, IPR
}

\begin{abstract}
"Un Psicoanálisis se inicia cuando el paciente siente interrumpido el relato de su vida" es un comentario a la ponencia clínica presentada en las VII Jornadas IARPP-E ${ }^{1}$ celebradas en Barcelona en 2017. Esta discusión se articula alrededor de dos ejes principales: La experiencia traumática y el trauma de desarrollo. $1^{\circ}$ ) Experiencia traumática: en este paciente, la muerte por sobredosis de su hermana; $2^{\circ}$. El trauma de desarrollo: en este paciente, una predominante dinámica del patrón relacional subyugador-subyugado, cuyas secuelas emocionales emergen cíclicamente. Desde un marco teórico-clínico psicoanalítico relacional, la experiencia psicoterapéutica ofrece una relación de respeto y consideración que nutre el desarrollo emocional del paciente. En este marco se van registrando experiencias emocionales del pasado, con el objetivo de aumentar la capacidad mental del analizado, para poder identificar, tolerar y transformar afectos derivados de dinámicas relacionales del presente.
\end{abstract}

Palabras clave: Inconsciente relacional, Implícito, Patrón relacional, Psicoanálisis relacional, Sentimiento de vergüenza, Trauma explícito, Trauma de desarrollo.

"Psychoanalyis begins when the patient feels his life story is interrupted" was the discussion to the clinical presentation at the 7th Conference of IARPP-E, held in Barcelona in 2017. The discussion is formulated around two main points: traumatic experience and developmental trauma. 1) Traumatic experience: for the patient in question, this was his sister's death from an overdose; 2) Developmental trauma: in this patient, the prevailing relational dynamic is that of opressor- oppressed, the emotional sequelae of which emerge cyclically. From a relational psychoanalytic theoretical and clinical framework, the psychotherapeutic experience offers a relationship of consideration and respect which nurtures the patient's emotional development. Within this framework, emotional experiences from the past are registered with the aim of expanding the analysand's mental space in order to identify, tolerate, and transform affects derived from present relational dynamics.

Key Words: Relational unconscious, Implicit, Relational pattern, Relational psychoanalysis, Affects of shame, Explicit trauma, Developmental trauma.

English Title: Psychoanalyis begins when the patient feels his life story is interrupted

Cita bibliográfica / Reference citation:

Velasco, R. (2017). Un Psicoanálisis se inicia cuando el paciente siente interrumpido el relato de su vida. Clínica e Investigación Relacional, 11 (3): 524-529. [ISSN 1988-2939] [Recuperado de www.ceir.info ] DOI: 10.21110/19882939.2017.110303

\footnotetext{
${ }^{1}$ Trabajo presentado en la reunión bienal de IARPP España celebrada en Barcelona, Abril 2017

${ }^{2}$ Rosa Velasco es Médico Psicoanalista de la SEP/IPA. Presidenta de IARPP-E. Miembro titular del IPR. Coautora del libro Delitos sexuales contra menores. Ed. Tirant Lo Blanch. Supervisa la Unidad asistencial Anorexia, Bulimia, Barcelona (ABB). Dirección de contacto: velascorosa@telefonica.net
} 
Voy a empezar mi comentario a esta brillante exposición clínica con la idea de que este paciente consigue sentir en este momento de su vida que él existe en continuidad en la mente de su analista (Orange, 1995, Velasco, 2008). La necesidad de existir en continuidad en la mente de alguien es la primera premisa que se cumple en este primer año de tratamiento. Ésta es también una necesidad universal que está presente en todos los seres humanos. Sin cubrirla, aunque solo sea de manera parcial, no podríamos haber conseguido seguir vivos (física y anímicamente). Podemos pensar que esta necesidad emocional está presente en muchos de nuestros pacientes ya desde la primera consulta. El sentimiento de que no contamos para los demás, y especialmente, el sentimiento de que no tenemos alguien en quien confiar, es una de las vivencias más comunes en la experiencia de demanda de ayuda psicológica.

Muchos psicoanalistas relacionales pensamos que un tratamiento psicoanalítico ayuda a que la persona pueda llegar a tener relaciones de calidad. Alcanzar la capacidad para lograr relaciones de calidad, con la pareja, con la familia, con las amistades o con la comunidad que nos acoge, es la mayor garantía de conseguir buenos índices de salud físicopsicológicos razonablemente aceptables para vivir la vida.

Este proceso terapéutico se inicia tras una consulta de urgencia. Este hombre dice sentirse muy deprimido después de que hace 5 días su novia decide cortar la relación. En el presente su padre está muy enfermo. Su hermana murió de manera traumática. Explícitamente el paciente se referirá a este hecho en su proceso analítico.

¿Cuál era el contexto personal de este paciente cuando su hermana muere por sobredosis? ¿Cómo piensa él que quedó la familia? ¿Que piensa él de su madre o de su padre ante la enfermedad y la muerte de su hermana? ¿Qué explica de si mismo ante esta realidad traumática de su pasado reciente?

Esta experiencia fue traumática para él y para sus padres. Pensar en todo ello en la sesión, interactuando con su analista, es terapéutico. Con el paciente registramos experiencias que dan cuenta de aquellos impactos emocionales que todavía no han sido suficientemente identificados, ni metabolizados ni transformados.

Como nos ha mostrado en estos días didácticamente el profesor Paul Wachtel, explorar con el analizado el contexto en el que se fue desarrollando un estado anímico defensivo de alerta, de desconfianza y de rigidez, nos será muy útil para ayudar al paciente a recuperar la trama de su vida. Este paciente decide empezar un psicoanálisis cuando siente que se interrumpió el relato de su vida. Podemos pensar que ese relato se rompió hace algunos expresa. Este material es para uso científico y profesional exclusivamente y puede contener información clínica sensible. Los editores no se responsabilizan de los contenidos de los autores. Dirigir las consultas sobre derechos y autorizaciones a ceir@psicoterapiarelacional.es 
años tras la muerte de su hermana por sobredosis. Ahora, en el presente y tras una nueva ruptura sentimental, él se desmorona y busca con urgencia una consulta psicológica.

La relación paciente-terapeuta, la dinámica psicoanalítica relacional, es según el profesor Joan Coderch, una buena "estructura de acogida" para dar cabida a los estados de ánimo del paciente que interfieren en el presente las dinámicas relacionales constructivas, tal como yo misma subrayaba en el prólogo de su libro (2014) Avances en Psicoanálisis Relacional.

En los momentos de mayor vulnerabilidad se activa la psicodinámica cíclica del miedo y de la desconfianza que cristaliza en formas rígidas de estar con uno mismo y con los demás.

¿Podríamos pensar que ahora el paciente tiene miedo de verse solo, sin nadie que lo acompañe en la vida? ¿Qué edad tiene su hija? Nos dice su terapeuta que están muy unidos ¿Cómo se las apaña Adrián (nombre con el que la terapeuta se refiere al paciente) cuando pasa tanto tiempo fuera de casa para poder co-construir con su hija el sentimiento de que ella existe de manera continuada en la mente de su padre?

Sensaciones interiores sobre su padre enfermo, temido y admirado; también él ahora se siente solo con todo esto; siente que se puede morir. Sensaciones que se pueden registrar ahora en el seno de su tratamiento con el objetivo de poder transformar rigidez en flexibilidad mental.

Tenemos una descripción muy detallada de lo que denominaré su "sufrimiento actual": "En mí hay algo que provoca reacciones adversas". Esta sería la onda expansiva del sentimiento de abandono que lo invadió tras la nueva ruptura sentimental. Podemos pensar en su dolor mental, también en un desarrollo emocional detenido en parte, desde su más tierna infancia, al sentirse el hijo varón de un padre colérico y de una madre víctima.

El patrón relacional subyugador-subyugado se pudo haber configurado en su mente como el marco relacional de desarrollo predominante en el que este paciente creció.

¿Este patrón relacional (subyugador-subyugado) se repitió en la dinámica de pareja que se rompió?

Parecería que él se confronta con la autoridad buscando justicia. La tolerancia de este hombre a formas autoritarias de relacionarse con él es pequeña. Nos comenta su terapeuta que la tolerancia a "las quejas" de la madre también es pequeña. ¿Podríamos tener algún dato más sobre como fue la relación con su novia? ¿Qué cree su terapeuta que resultó realmente y repetidamente insoportable para este paciente en la relación con su novia? expresa. Este material es para uso científico y profesional exclusivamente y puede contener información clínica sensible. Los editores no se responsabilizan de los contenidos de los autores. Dirigir las consultas sobre derechos y autorizaciones a ceir@psicoterapiarelacional.es 
¿Fue la vivencia de control? ¿Las quejas? ¿Un lado víctima (en él o en ella)? o ¿Un lado autoritario y controlador?

Pensar sobre estas cuestiones servirá para contextualizar al paciente y para poder reflexionar con él sobre sus propias reacciones emocionales.

Tener en mente su patrón relacional predominante será de gran ayuda para poder reflexionar con él sobre su trauma de desarrollo. Con ello estaremos contribuyendo a que el paciente aumente el espacio mental. Pensar sensaciones y sentimientos es desarrollar el proceso de subjetivación que estaba en déficit. Se facilita así el desarrollo emocional del paciente y se co-construye en el proceso terapéutico una mayor capacidad de autocuidado.

Ayudar a este paciente, tras "sentirse existiendo en continuidad en la mente de la analista", consistirá en aumentar la comprensión que este hombre tiene sobre si mismo. Observaremos como se vincula, las dificultades para establecer relaciones de calidad y exploraremos con él como son sus vínculos de seguridad. Su capacidad para relacionarse con sus iguales y para relacionarse en el terreno íntimo. Todo esto nos interesa como analistas.

De momento este paciente aparece como un "luchador incansable de las buenas causas". Trabaja protegiendo a los débiles en países en guerra. Necesita "violentamente" un reconocimiento constante de su quehacer. Además de la falta de un sentimiento de reconocimiento paterno pensaremos en la rabia que él debía sentir frente a su manera de observar y captar desde niño como sus padres se "ninguneaban". Junto con lo irresistible que debía ser entonces, y todavía ahora, seguramente sigue siéndo para él, el sentirse expuesto él mismo a "ser ninguneado". Este sería un implícito (Velasco, 2012), el inconsciente relacional o algunas secuelas emocionales de su trauma de desarrollo.

Él se mostraría en el presente como un salvador de las injusticias cometidas en un contexto relacional del pasado, el de su infancia. Todo ello a costa de "renunciar a su propia subjetividad". Una "posición en rol reversal" para sobrevivir en aquel contexto le llevó a un desarrollo emocional deficitario. Parecería que ahora en su contexto actual su manera espontánea de relacionarse le causa verdaderos problemas. Tiene miedo de que no le acepten, de que le rechacen, en palabras del paciente "En mi hay algo que provoca reacciones adversas". Se siente expuesto al rechazo y siente mucha rabia. En este momento veríamos este predominante patrón relacional emergiendo cíclicamente en el plano de sus relaciones profesionales. 
"Decir te quiero suena como un ruido extraño en mi familia" Con esta expresión él consigue transmitir que lo echa de menos, que es sensible a no sentirse importante en su contexto familiar. Sentir que le falta también es darle valor. Ayudarlo a relacionarse mejor, con su hija, con su familia, con sus compañeros en el trabajo y consigo mismo, consistirá en trabajar duro con su desconfianza. Algo así como atravesar una especie de "piel de lagarto", una especie de escudo protector, que desarrolló para auto-protegerse de las fallas empáticas contextuales del pasado.

Adrián llora sentidamente en la habitación íntima del análisis. Esta es una experiencia que él ahora se puede permitir en un marco de confianza, con la seguridad ya alcanzada de que su interlocutor (su terapeuta) no minimizará ni ridiculizará su sentimiento de vulnerabilidad, más bien al contrario. Él ya anticipa mentalmente, tras los primeros meses de tratamiento, que se sentirá acogido con su fragilidad. Los niveles de verdad han aumentado.

Los psicoanalistas relacionales pensamos que la fortaleza mental se construye aceptando y validando la propia fragilidad humana.

El sentimiento de vergüenza que está implícito (Velasco, 2008, 2012) se transforma de esta forma. De sentirse "ridículo y poco valioso" como se sentía en su pasado, en su casa, con su familia, o en el colegio, con su profesor de inglés y en muchos momentos de sus relaciones actuales, a sentirse "lleno de humanidad y valioso", en su dinámica relacional del presente, con su terapeuta.

Voy a concluir mi comentario resaltando una cuestión. La terapeuta pidió permiso al paciente para realizar este trabajo y exponerlo aquí en estas VII Jornadas IARPP-E de Barcelona.

El clima de respeto en el que se desarrolla este proceso analítico es una experiencia nueva con la que se nutre el desarrollo emocional de este paciente.

\section{REFERENCIAS}

Coderch, Joan (2013). Prólogo del libro de Raimundo Guerra "El clavo ardiendo" Ed. Octaedro.

Orange, Donna (1995). Emotional Understanding. New York. The Guilford Press.

Velasco, Rosa (2008). La vergüenza en la de-construcción/construcción del sentimiento de sí. En CelR www.ceir.org Vol. 2 (1) pp 58-67

Velasco, Rosa (2012). Trabajando con lo Implícito. Psicoanálisis Relacional. En CelR www.ceir.org Vol 6 (1) pp 23-31 
Velasco, Rosa (2014). Prólogo del libro de Joan Coderch "Avances en Psicoanálisis Relacional" Ed. Ágora Relacional.

Wachtel, Paul (2017). "El psicoanálisis relacional como una psicología contextual: Psicodinámica cíclica, bucles de retroalimentación, y vivir-en-el-mundo". Trabajo presentado en la VII Reunión Annual de IARPP-E, celebrada en Barcelona.

Wachtel, Paul (2017). "El inconsciente relacional: ¿Puede hacerse consciente? ¿Esto es necesario para que se produzca un cambio significativo?" Trabajo presentado en la VII Reunión Annual de IARPP-E, celebrada en Barcelona.

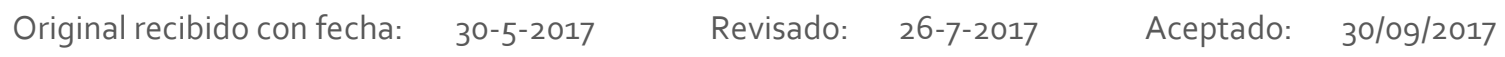

NOTAS:

${ }^{1}$ A cargo de Lucia Blanco Rejas: "En mi hay algo que provoca reacciones adversas", el trabajo que antecede a este en este número. 